\title{
Identification and characterization of a natural polymorphism in FT-A2 associated with increased number of grains per spike in wheat
}

\section{Priscilla Glenn}

University of California Davis

Junli Zhang

University of California Davis

Gina Brown-Guedira

North Carolina State University

Noah DeWitt

North Carolina State University

Jason P. Cook

Montana State University - Northern

Kun Li

University of California Davis

Jorge Dubcovsky ( $\nabla$ jdubcovsky@ucdavis.edu )

University of California Davis / HHMI https://orcid.org/0000-0002-7571-4345

\section{Research Article}

Keywords: wheat, grain, yield, increases, number

Posted Date: September 20th, 2021

DOI: https://doi.org/10.21203/rs.3.rs-906395/v1

License: (c) (i) This work is licensed under a Creative Commons Attribution 4.0 International License. Read Full License

Version of Record: A version of this preprint was published at Theoretical and Applied Genetics on November 26th, 2021. See the published version at https://doi.org/10.1007/s00122-021-03992-y. 
3

4 5

6

$7 \quad{ }^{1}$ Department of Plant Sciences, University of California, Davis, CA 95616, USA.

$8{ }^{2}$ USDA-ARS Plant Science Research, Raleigh, NC 27695, USA.

$9{ }^{3}$ Department of Crop and Soil Sciences, North Carolina State University, Raleigh, NC 27695, USA.

10

11

12

13 Priscilla Glenn: ORCID 0000-0002-2200-7241

14 Junli Zhang: ORCID 0000-0001-6625-2073

15 Gina Brown-Guedira: ORCID 0000-0002-1958-2827

16 Noah DeWitt: ORCID 000-0001-9055-993X

17 Jason Cook: ORCID 0000-0002-7753-6191

18 Kun Li: ORCID 0000-0001-8308-1560

19 Jorge Dubcovsky: ORCID 0000-0002-7571-4345

20

21

22

24

25

26

27 28

29

\section{\# Corresponding author}

Jorge Dubcovsky. E-mail: jdubcovsky@ucdavis.edu, Phone: +1-530-902-8178.

ORCID: 0000-0002-7571-4345.

4

Short Title: FT-A2 polymorphism increases grain number per spike

6

Key words: wheat, yield components, spikelet number, grain number, fertility 


\section{Abstract}

31 Increases in wheat grain yield are necessary to meet future global food demands. A previous

32 study showed that loss-of-function mutations in FLOWERING LOCUS T2 (FT2) increase

33 spikelet number per spike (SNS), an important grain yield component. Unfortunately, associated

34 reductions in fertility offset potential increases in grain number. Here, we report a natural

35 mutation resulting in an aspartic acid to alanine change at position 10 (D10A) associated with

36 significant increases in SNS and no negative effects on fertility. Using a high-density genetic

37 map, we delimited the SNS candidate region to a 5.2 Mb region on chromosome $3 \mathrm{AS}$ including

3828 genes. Among them, only FT-A2 showed a non-synonymous polymorphism (D10A) present

39 in two different populations segregating for the SNS QTL on chromosome arm 3AS. These

40 results, together with the known effect of the $f t-A 2$ mutations on SNS, suggest that variation in

$41 F T-A 2$ is the most likely cause of the observed differences in SNS. We validated the positive

42 effects of the A10 allele on SNS, grain number, and grain yield per spike in near-isogenic

43 tetraploid wheat lines and in an hexaploid winter wheat population. The A10 allele is present at

44 very low frequency in durum wheat and at much higher frequency in hexaploid wheat,

45 particularly in winter and fall-planted spring varieties. These results suggest that the FT-A2 A10

46 allele may be particularly useful for improving grain yield in durum wheat and fall planted

47 common wheat varieties.

\section{$49 \quad$ Key message}

50 We discovered a natural $F T-A 2$ allele that increases grain number per spike in both pasta and 51 bread wheat with limited effect on heading time. 


\section{Introduction}

54 Wheat is a global crop of major economic value and nutritional importance as it provides around $20 \%$ of the calories and protein consumed by the human population (http://www.fao.org/faostat/en/\#data/FBS). However, with ever changing environmental conditions and the rising human population, it is critical to increase wheat grain yield to meet future demands. Yield is a multifaceted trait that can be partitioned into several yield components, including spikes per unit of area, spikelet number per spike (SNS), grains per spikelet, and grain weight. Several genes have been identified that affect these grain yield components (Kuzay et al. 2019; Li et al. 2019; Poursarebani et al. 2015; Sakuma et al. 2019; Shaw et al. 2013; Simmonds et al. 2016; Wang et al. 2019). Unfortunately, many of the genes affecting SNS also have strong effects on heading date that limit their use in variety development. Significant yield penalties are usually observed for varieties heading before (e.g. incomplete grain filling) or after (e.g. increased risk of heat impacting seed filling) the optimum heading interval to maximize grain yield. For example, the vrn1-null mutant significantly increases SNS by delaying the transition of the inflorescence meristem to a terminal spikelet, but also delays the transition of the vegetative meristem to inflorescence meristem, resulting in a very late heading time (Li et al. 2019). Another good example is the main wheat photoperiod gene PHOTOPERIOD1 (PPD1), which shows a strong correlation between heading date and SNS in lines carrying different dosages of PPD1 loss-offunction mutations $\left(R^{2}=0.74\right)$ (Shaw et al. 2013). A correlation between heading date and SNS has also been observed in genes regulated by PPD1 such as the FLOWERING LOCUS T1 gene (FT1) (Brassac et al. 2021; Finnegan et al. 2018; Isham et al. 2021; Lv et al. 2014).

FT1 encodes a mobile protein that travels through the phloem and carries environmental signals from the leaves to the shoot apical meristem (SAM), where it forms a complex with 14-3-3 and FD-like proteins (Florigen Activation Complex) (Taoka et al. 2011). This complex binds to the promoter of the meristem identity gene VERNALIZATION1 (VRN1), promoting its expression and the transition from the vegetative to the reproductive phase in wheat (Li et al. 2015). Induction of FT1 also results in the upregulation of SUPPRESSOR OF OVEREXPRESSION OF

82 essential for spike development and stem elongation (Pearce et al. 2013). A deletion of FT-B1 in 
hexaploid wheat delays the transition to reproductive growth and increases SNS (Finnegan et al. 2018).

In addition to FT1, wheat has at least five FT-like paralogs designated as FT2 to FT6 (Lv et al. 2014), which have some overlapping functions but also varying degrees of sub-functionalization (Halliwell et al. 2016; Lv et al. 2014). FT2 is the most similar paralog to FT1 (78\% protein identity), but the two genes still exhibit marked differences in transcription and protein interaction profiles. Whereas the FT1 protein interacts with five out of the six wheat 14-3-3 proteins tested so far, FT2 failed to interact with any of these members of the Florigen Activation Complex (Li et al. 2015). The two genes also differ in their temporal and spatial transcription profiles. FT1 transcript levels in the leaves are upregulated earlier than $F T 2$ when plants are grown at room temperature, but only FT2 is induced when plants are grown for a long period at 4 ${ }^{\circ} \mathrm{C}$ (vernalization) (Shaw et al. 2019). Interestingly, FT2 is the only member of the wheat FT-like gene family that is expressed directly in the shoot apical meristem (SAM) and in the developing spike (Lv et al. 2014), in addition to leaves and elongating stems (Fig. S1).

Loss-of-function mutations in $F T 2$, identified in a sequenced mutant population of the tetraploid wheat variety Kronos (Krasileva et al. 2017), resulted in limited differences in heading time but significantly increased SNS (Shaw et al. 2019). Similar increases in SNS were observed in $f t-B 2$ natural mutants detected in hexaploid wheat (Gauley et al. 2021). The loss-of function mutation in the A-genome copy of FT2 (FT-A2) in Kronos was associated with significantly larger increases in SNS (10-15\%) than the mutation in the B-genome copy (FT-B2, 2-5\%). This difference in SNS was associated with much higher transcript levels of FT-A2 relative to FT-B2 in all tissues and developmental stages (Fig. S1). The increases in spikelet number in the double $f t-A 2 f t-B 2$ mutant (henceforth $f t 2$-null) were significantly larger than in the single $f t-A 2$ mutant confirming that the $F T-B 2$ gene still has a residual effect on SNS in spite of its lower transcript levels.

Unfortunately, the increase in SNS in the $f t-A 2$ mutant was associated with reduced fertility, offsetting the potential positive effects of the increase in SNS on total grain yield (Shaw et al. 2019). We hypothesized that strong selection in cultivated wheat for grain yield might have selected an FT-A2 variant with a positive effect on SNS, but without the associated negative effect on fertility. Analysis of natural variation in FT-A2 revealed an aspartic acid to alanine 
change at position $10(\mathrm{D} 10 \mathrm{~A})$ that was rare in tetraploid wheat but frequent in modern common wheat varieties, suggesting positive selection for the new allele. In this study, we characterized the effect of the D10A polymorphism on wheat heading time, SNS, grain number, and spike yield in different wheat classes and performed a high-density genetic map of the SNS QTL that identified $F T-A 2$ as the most likely candidate gene.

\section{Material and Methods}

Analysis of the exome capture data generated by the WheatCAP project using the assay developed by NimbleGen (Krasileva et al. 2017) and deposited in the Wheat T3 database (https://wheat.triticeaetoolbox.org/) revealed the existence of an A to C SNP within the FT-A2 coding region that resulted in the D10A polymorphism. We studied the effect of this SNP on heading time, SNS, grain number, and spike yield in two segregating populations in tetraploid and hexaploid wheat.

\section{Biparental mapping population in tetraploid wheat (Triticum turgidum ssp. durum)}

The tetraploid mapping population included $163 \mathrm{BC}_{1} \mathrm{~F}_{2}$ lines from the cross Kronos *2/Gredho (designated $\mathrm{KxG}$ hereafter). Kronos (PI 576168, FT-A2 D10 allele) is a semi-dwarf (Rht-B1b), with reduced photoperiod sensitivity $(P p d-A 1 a)$ spring wheat, whereas Gredho (PI 532239, FT$A 2$ A10 allele) is a tall (Rht-B1a), photoperiod sensitive (Ppd-A1b) spring landrace from Oman. We planted the KxG population as headrows in 2015-2016 season at the UC Experimental Field Station in Davis, CA with each row including on average five individual plants.

\section{Near isogenic lines of the $F T-A 2$ A10 allele from Gredho into Kronos}

We also evaluated the effect of the FT-A2 alleles in two sets of near isogenic lines (NILs). For the first set, we selected $F T-A 2$ heterozygous $\mathrm{BC}_{1} \mathrm{~F}_{2}$ and $\mathrm{BC}_{1} \mathrm{~F}_{3}$ lines from the cross Kronos *2/Gredho using the FT-A2 marker, and selected two sets of homozygous $\mathrm{BC}_{1} \mathrm{~F}_{3-4}$ homozygous A10 and D10 sister lines (H2-14 and H2-23). The Kronos isogenic line with the A10 allele was deposited in the National Small Grain Collection (PI 699107). We used the $\mathrm{BC}_{1} \mathrm{~F}_{3-5}$ grains produced by these plants for two field experiments, one at the University of California, Davis (UCD) and the other one at Tulelake (California northern intermountain region). Both field experiments were organized in a complete randomized design with plants as experimental units. 
142 Three to five spikes were measured per plant and averaged for 10 plants per genotype at the UC

143 Davis experiment. In the Tulelake experiment, 23-27 spikes per genotype were randomly

144 collected and used as experimental units in the statistical analyses.

145 In parallel, we backcrossed the A10 allele into Kronos for three additional generations (Kronos

$146 * 5 /$ Gredho), and then selected $\mathrm{BC}_{4} \mathrm{~F}_{2}$ NILs homozygous for the $\mathrm{A} 10$ and D10 alleles using the

147 FT-A2 molecular marker. The $\mathrm{BC}_{4} \mathrm{~F}_{3}$ seed was increased in the greenhouse in 2020 and the

$148 \mathrm{BC}_{4} \mathrm{~F}_{4}$ grains were used for a second field experiment at UCD in 2021 that used small plots (four

$1491-\mathrm{m}$ rows, $1.1 \mathrm{~m}^{2}$ ) as experimental units, organized in a randomized complete block design with

$150 \quad 12$ blocks.

151

152

153

154

155

156

157

158

159

160

161

162

163

164

165

166

167

168

169

170

\section{Biparental mapping population in hexaploid winter wheat}

The hexaploid population included 358 F5-derived recombinant inbred lines (RILs) derived from the cross between soft-red winter wheat lines LA95135 (CL-850643/PIONEER-

2548//COKER9877/3/FL-302/COKER-762) x SS-MVP57 (FFR555W/3/VA89-2252/TYLER//REDCOAT*2/GAINES). LA95135 is semidwarf (Rht-Dlb) and photoperiod sensitive $(P p d-D 1 b)$, whereas SS-MVP57 is tall $(R h t-D 1 a)$ and has reduced photoperiod sensitivity (Ppd-D1a) (DeWitt et al. 2021). This winter wheat population was previously genotyped and phenotyped as $1 \mathrm{~m}$ rows in the field at Raleigh, NC and Kinston, NC during the 2017-2018 season, and in Raleigh, Kinston, and Plains, GA in the 2018-2019 season (DeWitt et al. 2021). These locations will be referred to as Raleigh (Ral), Kinston (Kin), and Plains (Pla) followed by the harvest year (18 or 19).

\section{$F T-A 2$ marker development and allelic frequencies}

We targeted the FT-A2, D10A SNP at position 124,172,909 bp (RefSeq v1.0) on chromosome 3A with a Cleaved Amplified Polymorphic Sequence (CAPS) marker. Primers FT-A2-D10A forward and reverse (Table S1) amplify a fragment of $705 \mathrm{bp}$. After digestion with the restriction enzyme ApaI, the fragment amplified from the D10 allele remained undigested, whereas the fragment amplified from the A10 allele was digested into two fragments of 448 and $257 \mathrm{bp}$.

We used this marker to determine the frequency of the D10A mutation in 89 T. urartu, 82 T. turgidum ssp. dicoccoides, 32 T. turgidum ssp. dicoccon, 417 T. turgidum ssp. durum and 705 T. aestivum accessions summarized in Supplementary Appendix S1. Among the hexaploid lines, we 
171 included a collection of 238 landraces and varieties (He et al. 2019) and a set of 126 winter

172 wheats (T3/Wheat) genotyped by exome capture and with data for the FT-A2 D10A

173 polymorphism. We also used the $F T-A 2$ marker to genotype a panel of 242 spring wheats with

174 reduced photoperiod sensitivity (Zhang et al. 2018) and a panel of 99 varieties and modern

175 breeding lines from the Montana State University wheat breeding program (Supplementary

176 Appendix S1). The spring lines were further classified based on the planting season used in the

177 area where they were developed into those developed under spring planting (hereafter "DuS") or

178 under fall planting (hereafter "DuF"). A previous study has previously shown that DuS and DuF

179 groups are genetically differentiated using the 90K SNP array (Zhang et al. 2018)

180 (Supplementary Appendix S1).

181 High resolution genetic map

182 We developed a high-resolution map of the $\mathrm{KxG}$ population in two phases. In the first phase, we

183

184

185

186

187

188

189

190

191

192

193

194

195

196

197

198

199

identified two $\mathrm{BC}_{1} \mathrm{~F}_{3}$ plants from the $\mathrm{KxG} \mathrm{BC}_{1} \mathrm{~F}_{2}$ head rows, $\mathrm{H} 2$ and $\mathrm{D} 12$, which were

heterozygous for $F T-A 2$ candidate region. From these heterozygous lines we generated large segregating Heterogeneous Inbred Families (HIF) populations to identify recombination events within the FT-A2 candidate region. Phenotype screens of these recombinants were space-planted at least three inches apart in a completely randomized design. To generate additional markers in the candidate gene region, we developed markers for 11 genes on both sides of $F T$ - $A 2$ covering a region of $\sim 10 \mathrm{Mb}$ using the exome capture sequence data from Kronos and Gredho (Table S1).

\section{Statistical analysis}

In the tetraploid biparental population, we analyzed the effect of the $F T-A 2$ alleles with a 3 x 2 factorial ANOVA that included the genotypic variation at $P P D-A 1$ and $R H T-B 1$ as additional factors, since both genes are known to have pleiotropic effects on heading time and yield components. In the hexaploid winter wheat population, we analyzed the effect of the $F T-A 2$ in a $4 \times 2$ factorial ANOVA including the segregating genes PPD-D1, RHT-D1 and WHEAT ORTHOLOG OF APO1 (WAPO-A1), which was previously shown to affect SNS (Kuzay et al. 2019). Analysis of Variance was conducted with the "Anova" function in R package "car" (Fox et al. 2019) with type 3 sum of squares.

\section{Yeast two-hybrid assays}


209

210

211

212

213

Modified Gateway (Invitrogen) bait/prey vectors pLAW10 and pLAW11 (Cantu et al. 2013) and yeast strain Y2HGold (Clontech, Mountain View, CA, USA) were used in the yeast two-hybrid assays. pLAW10 is the Gateway version of pGBKT7 (GAL4 DNA-binding domain, BD) and pLAW11 is the Gateway version of pGADT7 (GAL4 activation domain, AD). For all Gateway compatible cloning, pDONR/Zeo (Life Technologies, Grand Island, NY, USA) was used to generate the entry vectors. All constructs were verified by sequencing. Yeast two-hybrid assays were performed according to the manufacturer's instructions (Clontech). Transformants were selected on SD medium lacking leucine $(-\mathrm{L})$ and tryptophan $(-\mathrm{W})$ plates and re-plated on SD medium lacking $-\mathrm{L},-\mathrm{W}$, histidine $(-\mathrm{H})$ and adenine $(-\mathrm{A})$ to test the interactions.

\section{Results}

\section{Natural variation in $\boldsymbol{F T}-\boldsymbol{A} \boldsymbol{2}$}

We used exome capture data deposited in the T3 database (https://triticeaetoolbox.org/wheat/) to explore the natural polymorphisms in FT-A2. We identified an A to C SNP at position $124,172,909$ in chromosome arm 3AS of the Chinese Spring (CS) RefSeq v1.0, which resulted in an amino acid change of aspartic acid (D) to alanine (A) at position 10 of the FT-A2 protein (henceforth, D10A). In the analyzed accessions of T. urartu, T. turgidum ssp. dicoccoides and T. turgidum ssp. dicoccon, we detected only the D10 allele (Table 1). D10 was also the only allele detected in all the other grass species we analyzed including Lolium perenne (AMB21802), Oryza sativa (XP_021310907), Zea mays (NP_001106251), and Panicum virgatum (APP89655), indicating that D10 is the ancestral grass allele. The Chinese Spring reference genome carries the derived A10 allele, but in this study, we describe the change from the ancestral to the derived allele rather than relative to the reference genome.

We also screened a collection of 417 T. turgidum ssp. durum accessions with a CAPS marker for the D10A polymorphism (see Material and Methods) and found that only $0.7 \%$ carried the A10 allele (Table 1). Two of the three accessions with the A10 allele were from Oman (PI $532239=$ 'Gredho' and PI 532242, 'Musane and Byaza') and the other one was from Turkey (PI 167718), suggesting that the A10 allele is almost absent from modern Western durum germplasm.

We detected a higher frequency of the A10 allele (56.5\%) among 705 T. aestivum ssp. aestivum lines (Table 1). This overall frequency was similar to that detected in a worldwide collection of 
230

231

232

233

234

235

236

237

238

239

240

241

242

243

244

245

246

247

248

249

250

251

252

253

254

255

256

257

258

landraces and varieties combining winter and spring lines (59.7 \%) (He et al. 2019). We also analyzed the frequency of the D10A polymorphisms in two collections with known growth habit, and found a higher frequency of the A10 allele among the winter lines (81.7\%) than among the spring lines (44.9\%, Table 1). Among the 341 spring wheat lines genotyped with the FT-A2 marker, we found that varieties developed under fall-planting (DuF or long cycle) had a significantly higher frequency of the A10 allele (58.4\%) than those developed under springplanting (DuS or short cycle, 34.4\%, Table 1). A complete list of the accessions used in these calculations is available in Supplementary Appendix 1, and a summary of the frequencies is presented in Table 1.

\section{Effect of the D10A polymorphism in tetraploid wheat}

To test the effect of the D10A polymorphism on SNS, we used the diagnostic CAPS marker to screen $163 \mathrm{BC}_{1} \mathrm{~F}_{2}$ plants from the $\mathrm{KxG}$ population segregating for this polymorphism. We also genotyped this population with markers for the segregating RHT-BI (Guedira et al. 2010) and $P P D-A 1$ (Wilhelm et al. 2009) genes, which can also affect SNS. Plants were grown in the field in the 2015-2016 season in Davis, CA and were phenotyped for individual plant height (HT), days to heading (DTH), and spikelet number per spike (SNS, Table 2).

The three-way factorial ANOVAs including FT-A2, RHT-B1, and PPD-A1 as factors showed significant effects for SNS, HT, and DTH and no significant interactions for any of the traits. As expected, RHT-BI showed the strongest effect on plant height and $P P D-A 1$ on heading time, although both genes affected both traits (Table 2). The strongest effect on SNS was detected for $P P D-A 1$, but a significant effect was also detected for FT-A2 (Table 2), with plants homozygous for A10 showing $6.4 \%$ higher SNS than those homozygous for D10 allele (Table 2). The differences in SNS between the FT-A2 alleles were larger in the late flowering plants homozygous for the photoperiod sensitive allele from Gredho ( 2.3 spikelets/spike) than in the early flowering plants homozygous for the Kronos allele for reduced photoperiod sensitivity (1.0 spikelets per spike), but the interaction was not significant.

\section{Effect of the $F T-A 2$ alleles in Kronos near isogenic lines}


259 To analyze the effect of the D10A polymorphism independently of the variability generated by

260 other major genes, we evaluated two sets of near isogenic lines in field experiments in 2020 at

261

262

263

264

265

266

267

268

269

270

271

272

273

274

275

276

277

278

279

280

281

282

283

284

285

286

287

288

$\mathrm{UCD}$ and Tulelake $\left(\mathrm{BC}_{1} \mathrm{~F}_{3-5}\right.$ sister lines), and in 2021 at $\mathrm{UCD}\left(\mathrm{BC}_{4} \mathrm{~F}_{2: 4}\right.$ sister lines, see Material and Methods). In the 2020 experiment at UCD, lines with the A10 allele (PI 699107) showed large and significant increases in SNS (13.8\%), grain number per spike (GNS, 31.7\%), grains per spikelet (16.1\%, also referred to as fertility) and grain yield per spike (33.0\%) relative to the sister lines homozygous for the D10 allele (Table 3). The results from this experiment were consistent between two independent pairs of $\mathrm{BC}_{1} \mathrm{~F}_{3-5}$ sister lines $(\mathrm{H} 2-14$ and $\mathrm{H} 2-23$, Table 3).

The experiments in Tulelake (Northern California, spring planting) using $\mathrm{BC}_{1} \mathrm{~F}_{3-5}$ sister lines from family H2-14, also showed increases in SNS (4.0\%), GNS (5.4\%), grains per spikelet $(1.7 \%)$, and grain yield per spike (10.5\%) associated with the A10 allele. However, the magnitude of the differences between the $F T$-A2 alleles was smaller than those observed at the 2020 UCD experiment under fall planting. Only the differences in SNS were statistically significant in Tulelake (Table 3).

For the $2021 \mathrm{UCD}$ experiment using sister $\mathrm{BC}_{4} \mathrm{~F}_{2: 4}$ lines, we had more grains available and we were able to use small plots $\left(1.1 \mathrm{~m}^{2}\right)$ as experimental units, with 12 replications per genotype. Lines with the FT-A2 allele headed on average $0.8 \mathrm{~d}$ later than those with the D10 allele $(P=$ $0.0252)$ and showed significant increases in SNS $(5.7 \%, P=0.0011)$ and GNS $(6.3 \%, P=$ 0.0168 , Table 3). In this experiment we did not detect significant differences in grains per spikelet $(P=0.7919)$. We observed a negative correlation between average GNS and grain weight across the 24 plots $(R=-0.61)$ and a significant negative effect of the A10 allele on kernel weight $(-7.8 \%, P=0.0002)$. The negative effect on grain weight offset the positive effect of the A10 allele on grain number resulting in non-significant differences in grain weight per spike (Table 3 ). We harvested the complete plots and measured grain yield per plot and the average yields of the two genotypes were almost identical: $\mathrm{D} 10=1,254 \pm 26$ and A10 $=1,251 \pm$ $32 \mathrm{~g}(P=0.9103)$.

\section{The A10 allele has a positive effect on SNS and spike yield in winter wheat}

To analyze the effect of the D10A FT-A2 alleles in winter wheat, we used phenotypic data available from 358 F5-derived RILs from the cross between soft-red winter wheat lines LA95135 
and SS-MVP57 (DeWitt et al. 2021) and genotypic data for the FT-A2 marker developed in this study. This population was also segregating for $P P D-D 1, R H T-D 1$, and $W A P O-A 1$, which were included as factors together with FT-A2 in a $4 \times 2$ factorial ANOVA.

Plants carrying the FT- $A 2$ allele A10 (SS-MVP57) headed on average 1.7 days later $(P<0.001$, Fig. 1a) and had 0.6 more spikelet per spike (5.1\% increase, $P<0.001$, Fig. 1b) than plants carrying the D10 allele (LA95135). The differences in SNS were significant in all tested locations. The A10 allele was also associated with an average 5.8\% increase in GNS in the two locations where this trait was measured, but the differences were significant only for the Pla19 location (2.7 more grains per spike, $P<0.001$, Fig. 1c). The A10 allele was also associated with a $1.2 \%$ increase in the number of grains per spikelet but the differences were not significant (Fig. 1d). The differences in SNS were associated with a significant $4.6 \%$ increase in average spike yield associated with the A10 allele in two out of the three tested locations $(P<0.001$, Fig. 1e). To delimit the QTL for SNS in this population, we performed ANOVAs for markers flanking FT-A2 (Table S2). Marker S3A_116,149,133 located 1.6 cM (8.0 Mb) distal to FT-A2 and marker S3A_194,830,543 located $3.5 \mathrm{cM}(70.7 \mathrm{Mb})$ proximal to FT-A2 still showed highly significant differences in SNS, but both markers exhibited a decrease in the ANOVA $F$ values relative to FT-A2 (14\% and $16 \%$, respectively). Based on these results, we delimited a $5.1 \mathrm{cM}$ $(78.7 \mathrm{Mb}$ ) confidence interval for the SNS QTL in this population including FT-A2.

\section{High resolution mapping of the SNS QTL on chromosome 3AS}

The previous results showed that the haplotypes associated with the FT-A2 D10 and A10 alleles have a significant effect on SNS. To narrow down the candidate gene region and explore the linkage between the $F T-A 2$ D10A polymorphism and the differences in SNS, we generated a high-density map of the 3AS chromosome region in tetraploid wheat using a total of 3,161 $\mathrm{BC}_{1} \mathrm{~F}_{3}, \mathrm{BC}_{1} \mathrm{~F}_{4}$, and $\mathrm{BC}_{1} \mathrm{~F}_{5}$ plants derived from the $\mathrm{KxG}$ population. These plants were screened in separate batches over three years using flanking markers 3A-117.83 and 3A-127.82 (numbers indicate coordinates in RefSeq v1.0 in $\mathrm{Mb}$ ). Within this $9.9 \mathrm{Mb}$ region including FT-A2 (124.17 $\mathrm{Mb})$, we identified 76 recombination events corresponding to a genetic distance of $1.58 \mathrm{cM}(6.26$ $\mathrm{Mb}$ per $\mathrm{cM})$. One of these recombination events (H2-6-\#14-5) was detected in the progeny test of 
primary recombinant $\mathrm{H} 2-\# 6$, which explains the presence of two close recombination events in this line (Table 4).

In addition to the molecular marker for the FT-A2 D10A SNP and the two flanking markers, we developed eight more KASP and CAPS markers in the candidate region (Table S1) and used them to genotype plants carrying recombination events in the region. The lines with the 10 closest recombination events to $F T-A 2$ are presented in Table 4 together with the results of the field progeny tests for SNS. Progenies of the lines H2-\#6 and H2-14\#17-2 heterozygous for FT$A 2$ showed significant differences in SNS $(P<0.01)$ between lines homozygous for the two parental alleles, whereas progeny tests for the eight lines homozygous for FT-A2 did not show significant difference in SNS between parental alleles in the heterozygous flanking regions (Table 4). Average SNS were as expected, with the lines homozygous for the A10 allele having 1.3 more spikelets on average than the lines homozygous for the D10 allele.

The phenotype of the critical recombinant line \#18-5 with the closest distal recombination event to $F T-A 2$ was validated in a separate experiment in Davis in 2021 (Table S3). In this experiment, control lines showed highly significant differences in SNS $(P<0.0001)$ confirming that the differences in SNS were detectable in this experiment. By contrast, there was no significant difference between the sister lines with and without the recombination event \#18-5, with both lines showing SNS values similar to the control line with the Gredho allele (Table S3). Taken together, these results confirmed that the causal gene for the 3AS QTL for SNS was proximal to the marker located at CS RefSeq v1.0 coordinate 120,227,651 (Table 4).

We identified an additional line $\left(\mathrm{BC}_{1} \mathrm{~F}_{4} \mathrm{H} 2-18\right.$ \#28-4) with a closer recombination event to $F T$ $A 2$ in the proximal region between $F T-A 2-R 1$ and $3 A-125.4$, but we did not have enough grains to evaluate it with the other lines listed in Table 4 . We planted a separate field experiment at Tulelake in the spring of 2020, in which we included homozygous sister lines \#28-4-1 and \#284-3 that were fixed for either the Kronos or Gredho alleles in the segregating proximal region (Table 5). As an additional control, we included sister lines derived from plant \#17-2 (Table 4) that were either homozygous for the FT-A2 D10 (\#17-2-18) or A10 allele (\#17-2-22, Table 5). These two lines showed highly significant differences in SNS $(P<0.0001$, Table 5$)$ confirming that it was possible to detect differences between the two $F T-A 2$ alleles in this experiment. By contrast, there was no significant difference between the H2-18 \#28-4 recombinant sister lines, 
confirming that the candidate gene was still linked to $F T-A 2$ (Table 5). Based on this result, we established a closer proximal flanking marker (3A-125.4), and reduced the candidate region for the 3AS QTL to a 5.2 Mb interval between coordinates 120,227,651 and 125,402,254 (Table 5).

\section{Genes in the candidate gene region for the 3AS QTL for SNS}

The annotated Chinese Spring reference genome region (RefSeq v1.1) between the two flanking markers defined in the previous section encompasses 28 high-confidence genes (including flanking genes TraesCS3002G141000 and TraesCS3002G143700). The exome capture data revealed non-synonymous SNPs between Kronos and Gredho in only three out of the 28 genes, including the D10A polymorphism in $F T-A 2$. The other two genes are described briefly below.

TraesCS3A02G142200 encodes a leucine-rich repeat receptor-like protein kinase, so it is difficult to predict its potential effects. The predicted R872H amino acid change in Kronos (RefSeq v1.1 3AS $121,646,195)$ is in a conserved region close to the end of the protein ( 893 amino acids) and has a BLOSUM62 score of 0 , predictive of a low probability of changes in protein structure or function. The R872H polymorphism was not detected in the parental lines LA95135 and SSMVP57 of the hexaploid winter wheat populations segregating for the 3AS SNS QTL (Table S2), so we ruled out R872H as the causal polymorphism for the SNS phenotype.

TraesCS3A02G143600 encodes a short peptide (104 amino acids) with a polymorphism in Kronos that generates a premature stop codon (S59*, RefSeq v1.1 3AS 125,094,949 C to A). However, the predicted protein in Gredho also seems to be truncated since it is much shorter (104 amino acids) than the orthologous protein in wild emmer (XP_037404892.1, 483 amino acids) or T. urartu (EMS53367.1, 348 amino acids). In addition, the 104 amino acids in Gredho showed no similarity to other plant proteins in the GenBank nr database in species outside the genus Triticum, suggesting that TraesCS3A02G143600 encodes a non-functional protein in both Kronos and Gredho. Similar to R872H, the S59* polymorphism was not detected in winter lines LA95135 and SS-MVP57, providing additional evidence that this polymorphism is not critical for the SNS QTL on chromosome arm 3AS. 
In summary, the D10A polymorphism in TraesCS3A02G143100 (FT-A2) was the only nonsynonymous SNP identified in the candidate gene region that co-segregated with the differences in SNS in both the LA95135 x SS-MVP57 and Kronos x Gredho populations.

\section{Effect of the D10A polymorphism on FT-A2 interactions with 14-3-3 proteins}

Previous results have shown positive interactions between FT1 and six of the seven 14-3-3 proteins tested whereas FT-A2 did not interact with any of the 14-3-3 proteins (Li et al. 2015). This was a puzzling result because all other four FT-like genes showed positive interactions with at least one 14-3-3 protein. Since the original study was done using only the FT-A2 D10 allele, we decided to explore the effect of the A10 allele. In this study, both FT-A2 proteins encoded by the D10 and A10 allele failed to interact with any of the six tested 14-3-3 proteins, whereas the FT1 positive control showed a strong interaction signal (Fig. S2). No autoactivation was observed in the negative controls. Given the lack of interactions between both FT-A2 alleles and any of the tested 14-3-3 protein, we have initiated $\mathrm{Y} 2 \mathrm{H}$ screens to test if there are other protein partners of FT-A2.

\section{Discussion}

\section{Candidate gene and causal polymorphism}

Spikelet number per spike is determined early after the transition from the vegetative to the reproductive phase, when the spike meristem transitions into a terminal spikelet (Li et al. 2019). This limits the influence of later environmental variability on SNS relative to GNS or grain weight, which are affected by fertility, grain abortions, and conditions affecting grain filling until the end of the season. As a result, SNS has a higher heritability $(h>0.8)$ than other yield component traits (Kuzay et al. 2019; Zhang et al. 2018). This high heritability helped us to Mendelize this trait and to develop a high-resolution map for the differences in SNS.

Using this high-density map, we delimited a 5.2 Mb candidate gene region on chromosome arm 3AS including 28 annotated high-confidence genes in CS, including three with non-synonymous polymorphisms between Kronos (D10) and Gredho (A10): TraesCS3A02G142200(R872H), TraesCS3A02G143100 (D10A) and TraesCS3A02G143600 (S59*). To test if the S59* and 
R872H polymorphisms were present in hexaploid varieties with the D10 allele, we compared the available sequences for this region in the wheat pangenome (Walkowiak et al. 2020). The 124,172,909-A allele (D10) was detected in CDC Landmark, Lancer, and Spelt, whereas the 124,172,909-C (A10) SNP was present in CS, Julius, Jagger, CDC Stanley, ArinaLRFor, Mace, Norin 61, and SY Mattis. The S59* and R872H polymorphisms were not detected in any of these hexaploid wheats, suggesting that these two SNPs originated in durum wheat, and that the A10 mutation occurred in a haplotype different from the one present in modern durum wheat varieties (henceforth S59*-R872H haplotype).

Based on the previous result, it was not surprising that the S59* and $\mathrm{R} 872 \mathrm{H}$ polymorphisms were not detected in LA95135 (D10) and SS-MVP57 (A10), the parental lines of the hexaploid winter wheat population segregating for the 3AS SNS QTL. Gene TraesCS3A02G143600 showed no polymorphisms between LA95135 (D10) and SS-MVP57, whereas TraesCS3A02G142200 had only one synonymous polymorphism, suggesting that TraesCS3A02G143600 and TraesCS3A02G142200 are unlikely candidate genes for the SNS QTL. After the elimination of these two genes, FT-A2 is the only other gene in the candidate region that has a non-synonymous polymorphism (D10A) linked to the differences in SNS in both mapping populations. Since we only explored the coding regions, we cannot rule out the possibility of polymorphisms in regulatory regions within the candidate gene region affecting the number of spikelets per spike. However, the genetic data presented here, together with previously published results showing that loss-of-function mutations in FT-A2 affect SNS in wheat (Shaw et al. 2019), point to FT-A2 as the most likely candidate gene for the SNS QTL.

The D10A amino acid change in FT-A2 has a BLOSUM 62 score of -2 and is located in a conserved region of the protein, suggesting a high probability of an effect on either protein structure or function. To test if any other polymorphisms in $F T-A 2$ were associated with the D10A polymorphism, we compared the available exons, introns, $5^{\prime}$ ' upstream region (5,000 bp) and 3' downstream region (2,000 bp) of FT-A2 in genomic sequences of hexaploid wheat (Walkowiak et al. 2020). We did not find any additional SNPs to differentiate the varieties with the D10 allele (CDC Landmark, Lancer and Spelta) from those carrying the A10 allele (CS, Julius, Jagger, CDC Stanley, ArinaLRFor, Mace, Norin 61, and SY Mattis) in the analyzed region. Although we cannot completely rule out the possibility of polymorphisms located in regulatory regions outside the investigated region, the available evidence points to D10A as the 
most likely causal polymorphism. A conclusive test of this hypothesis will require the editing of the $\mathrm{A} 124,172,909 \mathrm{C}$, but this is not simple because this is a transversion, and currently available plant gene editors are not efficient to edit transversions. New prime editing technologies (Anzalone et al. 2019) may solve this problem once they become more efficient in plants (Lin et al. 2020).

\section{Differential recombination rates within the candidate gene region}

The distribution of recombination events $(\mathrm{RE})$ in the $10 \mathrm{Mb}$ region between the flanking markers used in this study was not uniform. In the $2.4 \mathrm{Mb}$ distal to the candidate gene region (117.8 to 120.2 Mb, 14 genes), we detected 56 RE resulting in an average of $23.3 \mathrm{RE} / \mathrm{Mb}$ or $4.0 \mathrm{RE} /$ gene. In the $2.4 \mathrm{Mb}$ proximal to the candidate region (125.4 to $127.8 \mathrm{Mb}, 13$ genes), we detected 20 $\mathrm{RE}$ resulting in a frequency of 8.3 $\mathrm{RE} / \mathrm{Mb}$ or $1.5 \mathrm{RE} /$ gene. Surprisingly, not a single RE was detected in the $5.2 \mathrm{Mb}$ central candidate region (120.2 to $125.4 \mathrm{Mb}, 28$ genes), despite being twice as large and including twice the number of genes as the flanking regions. Recombination events occur mainly in gene regions (Darrier et al. 2017), so we would have expected to find 39 of the $76 \mathrm{RE}$ within the candidate region if $\mathrm{RE}$ were distributed proportionally to the number of genes. The same number would be expected if RE were distributed proportionally to the length of the interval.

To explore if this lack of recombination in the central region was caused by a structural rearrangement, we used the sequenced genome of the tetraploid variety Svevo (Maccaferri et al. 2019) that showed the same SNPs as the Kronos exome capture across the candidate gene region. Since Gredho showed very few polymorphisms with CS across the candidate gene region, we compared the genomes of CS (A10) and Svevo (D10) in this region. In Svevo, we found orthologs to the 28 high confidence genes present in CS, with the exception of TraesCS3A02G142500 that was present in the correct position and strand in Svevo (100\% identical over all its length) but was not annotated. All the genes were in the same orientation in $\mathrm{CS}$ and Svevo, and the total length of the region was similar in both species $(5.2 \mathrm{Mb})$, suggesting that no major structural rearrangements occurred in the candidate gene region.

Finally, we did a BLAST comparison of all the Svevo genes to a Kronos scaffold assembly from the Earlham Institute, U.K. and were able to detect 27 of the 28 genes with $100 \%$ identity. The 
only exception was TRITD3Av1G056250 (ortholog of CS TraesCS3A02G142600), for which we only detected the B-genome homeolog in Kronos. These results suggest the Kronos genome is not very different from Svevo in this region. We currently do not know the cause of the reduced recombination frequency between 121.5 and $125.1 \mathrm{Mb}$ in the Kronos $\mathrm{x}$ Gredho population, but since no pseudomolecule assembly of Kronos or Gredho are available, we cannot rule out the possibility of structural rearrangements in this region in these two varieties.

\section{Effect of $F T-A 2$ D10A polymorphism on heading time and fertility}

Wheat varieties are selected to flower within a narrow time window to maximize grain productivity. This limits the introgression of loss-of-function alleles that have beneficial effects on SNS but generate large delays in heading time, such as those in VRN1 (Li et al. 2019) or PPD1 (Shaw et al. 2013). By contrast, the FT-A2 A10 allele has a positive effect on SNS and limited effect on heading time. Even when loss-of-function mutations in $f t-A 2$ and $f t-B 2$ were combined in Kronos, the delay in heading time was only 2-4 days (Shaw et al. 2019). In this study, the D10A polymorphism showed small effects on DTH in the different genetic backgrounds, ranging from a non-significant difference in the initial Kronos x Gredho population (Table 2), a marginally non-significant difference of $0.8 \mathrm{~d}(P=0.053)$ in the 2021 field experiment comparing Kronos isogenic lines, and an average difference of $1.7 \mathrm{~d}$ in the winter wheat population (Fig. 1A).

An important limitation for the utilization of the $f t-A 2$ loss-of-function mutation for wheat improvement was its negative effect on fertility (Shaw et al. 2019), which offset its positive effect on SNS. This motivated our initial search for $F T-A 2$ natural variants that separated the positive effects on SNS from the negative effects on fertility. Results presented in this study show that the positive effect of the A10 polymorphism on SNS were translated into positive effects on GNS in both the winter wheat population (Fig. 1e) and in the spring NILs (Table 3). These results suggest that the A10 allele is not associated with negative effect on fertility. This hypothesis was further supported by the higher number of grains per spike observed in the lines carrying the A10 allele in the different field experiments, although the differences were significant only in the two Kronos NILs evaluated in the field in 2020 (Table 3). These results provide a good example of the value of using natural variants selected by breeders to identify mutations that optimize specific traits with limited negative pleiotropic effects. 
495 It was encouraging to see that the positive effect of the A10 allele on SNS and GNS was expressed in both winter (Fig. 1) and spring wheats (Table 3), and among the latter in both spring

497 and fall planted spring wheats. However, the magnitude of the increases in SNS, GNS and spike

498 yield associated with the A10 allele varied among experiments, suggesting that the effects of this

499 FT-A2 polymorphisms on these traits are modulated by the environment. We also observed

500 variable effects of the A10 polymorphisms on grain weight. Whereas no significant effects were

501 detected for this trait in the experiments performed in UCD and Tulelake in 2020, we detected a

502 significant reduction in grain weight in field experiment performed at UCD in 2021, which offset

503 the gains in GNS (Table 3).

504 Similar observations have been reported for $W A P O-A 1$, the causal gene of a wheat SNS QTL on 505 the long arm of chromosome 7AL (Kuzay et al. 2019). Increases in SNS associated with the 506 favorable Wapo- $A 1 \mathrm{~b}$ allele were translated into significant increases in grain yield only when the 507 favorable $W A P O-A 1$ allele was present in productive genetic backgrounds and the plants were 508 grown in a favorable environment. When the Wapo-A1b allele was present in poorly adapted 509 varieties or when the lines were grown under limiting watering conditions, the plants did not 510 have enough resources to fill the extra grains, resulting in a negative correlation between grain 511 number and grain weight that limited the gains in grain yield (Kuzay et al. 2019). A study with 512 elite CIMYT lines also highlighted the importance of genetic-by-environment interactions on the 513 trade-offs between grain number and grain weight (Quintero et al. 2018). We hypothesize that 514 environmental differences between our 2020 and 2021 field trials may have contributed to the 515 516 observed differences in grain weight, in spite of the positive effects of the A10 allele on SNS and GNS detected in both years (Table 3). FT- $A 2$ as a candidate gene for previously published SNS QTLs on chromosome arm 3AS A QTL for DTH (Qncb.HD-3A) was previously mapped on chromosome 3A within a $400 \mathrm{Mb}$ 520 interval including FT-A2 (DeWitt et al. 2021) in the LA95135 x SS-MVP47 population. We 521 found in this study that LA95135 carries the D10 allele and SS-MVP47 the A10 allele, and after 522 genotyping the population with the FT-A2 marker, we found that the A10 allele was associated 523 not only with a slight delay in heading time but also with higher SNS, GN, and grain yield per 
524 spike (Fig. 1). The similar pleiotropic effects of the SNS QTL in the winter wheat population and

525 the Kronos $\mathrm{x}$ Gredho population, together with the overlapping mapping regions, suggest that the

526 FT-A2 D10A polymorphism may have contributed to the Qncb.HD-3A identified in the

527 LA95135 x SS-MVP47 population.

528 An additional QTL for DTH was identified in the Avalon x Cadenza population (U.K.) on

529 chromosome arm 3AS around the peak marker BS00021976 (169 Mb RefSeq v1.0) (Martinez et

530 al. 2021). This QTL interval (60 Mb at each side of BS00021976) includes 536 annotated genes,

531 among which the authors proposed FT-A2 as a candidate of particular interest. Using our FT-A2

532 marker, we established that both Avalon and Cadenza carry the A10 allele, so we conclude that

533 the D10A polymorphism is not the cause for the observed differences in DTH. Martinez et al.

534 (2021) suggested that differences in FT-A2 transcript levels may contribute to the differences in

535 DTH, but more precise mapping of the QTL will be necessary to support this hypothesis.

536 Several QTLs for grain yield components have been reported in different regions of chromosome

$5373 \mathrm{AS}$ in a recombinant inbred chromosome line from the cross between cultivar Cheyenne and a

538 substitution of chromosome 3A of Wichita in Cheyenne (CNN(Wichita-3A)) (Ali et al. 2011;

539 Campbell et al. 2003; Dilbirligi et al. 2006). QTLs for grain yield and grain number per square

540 meter were mapped in a region between markers barc86 and barc67 (54.4 to 464.3 Mb RefSeq

541 v1.0, "Region 2") which encompasses the FT-A2 locus. However, both Cheyenne and

$542 \mathrm{CNN}($ Wichita-3A) have the A10 allele of FT-A2 (Supplementary Appendix S1), suggesting that

543 a different gene (or a different polymorphism in FT-A2) was the cause of this QTL.

544

545

\section{$F T-A 2$ allele frequencies and breeding applications}

546 The FT-A2 alleles show contrasting frequencies in durum and common wheat, with the A10

547 allele present in less than $1 \%$ of the durum accessions and in $56 \%$ of the common wheat varieties

548 analyzed in this study (Table 1). We currently do not know if the A10 allele originated in the few

549 durum accessions carrying this allele in Oman and Turkey, or if these represent later

550 introgressions from hexaploid to tetraploid wheat. Either way, since the appearance or transfer of

551 the A10 allele to common wheat, its frequency increased rapidly suggesting that it was favored

552 by breeders in common wheat breeding programs. 
553 The low frequency of the A10 allele in durum wheat could be a result of an hexaploid wheat 554 origin combined with lack or infrequent transfers of genes from hexaploid to tetraploid wheat.

555 However, it can also be the result of selection for larger grains and indirect selection for reduced 556 GNS in environments showing a negative correlation between these two traits. Similar to $F T-A 2$, 557 the Wapo-Ala allele for low SNS is almost fixed in durum wheat, whereas the Wapo-A1b allele 558 for high-SNS is found at high frequencies in hexaploid wheat (Kuzay et al. 2019). We interpret 559 this similar asymmetric distribution of $W A P O-A 1$ and FT-A2 alleles for SNS in common and 560 durum wheat as indirect support to the hypothesis that selection for larger grains may result in 561 indirect selection for reduced SNS.

562 Among hexaploid spring wheats, we also observed significant differences in the distribution of 563 the FT-A2 alleles, with a larger frequency of the A10 allele among spring varieties developed 564 under a long growing cycle (DuF, 58.4\%) than among those developed under a short growing cycle (DuS, 34.4\%). We speculate that longer cycles may provide more resources to fill the extra grains associated with the A10 allele, facilitating the translation of the difference in SNS into differences in grain yield. This in turn, may result in a stronger selection pressure for the A10 allele in the fall-planted programs. This idea is indirectly supported by the high frequency of the A10 allele among the US winter wheat varieties (Table 1, 81.7\%). Additional experiments with D10 and A10 NILs in different genetic backgrounds tested in different spring-planted and fall571 planted locations will be necessary to test this hypothesis.

572 The high frequency of the A10 allele in the winter wheats and fall-planted spring wheats

573 provides additional evidence that this allele has positive effects in those regions. However, as the 574 frequency of the A10 allele increases, the number of varieties that can benefit from its 575 introgression decreases. By contrast, the A10 allele is almost absent from modern durum wheat 576 breeding programs, and may represent a good opportunity to benefit a large proportion of the 577 germplasm in the durum wheat programs. To facilitate the testing and introgression of the A10 578 allele into durum wheat breeding programs, we deposited the Kronos NIL with the A10 allele in 579 the NSGC (PI 699107). Kronos, is a modern durum wheat variety with excellent pasta quality, 580 which makes it a better donor parent than Gredho.

581 Our preliminary results suggest that the A10 allele may be more beneficial in fall planted than in 582 the spring planted durum wheat programs, but additional experiments are necessary to test this 
583 hypothesis. It will be also interesting to investigate the combined effect of the A10 allele with

584 alleles from other genes that also result in increases in SNS such as Wapo-Alb (Kuzay et al.

585 2019) and the Elf3 allele from T. monococcum (Alvarez et al. 2016).

586 In summary, the genetic information provided in this study, together with the previous mutant

587 information, provides strong evidence that FT-A2 is the causal gene for the differences in SNS,

588 GNS, and spike yield associated with this region on chromosome arm 3AS. The identification of

589 the likely causal polymorphism (D10A) and the development of a perfect marker for this

590 polymorphism can accelerate the deployment of this favorable allele in wheat breeding programs

591 worldwide.

592

593 Declarations

$594 \quad$ Funding

595 This project was supported by the Agriculture and Food Research Initiative Competitive Grants 596 2017-67007-25939 (WheatCAP) from the USDA National Institute of Food and Agriculture and 597 by the Howard Hughes Medical Institute. Priscilla Glenn acknowledges support from NSF

598 Graduate Research Program Fellowship Grant 2036201.

599

600 Acknowledgements

601 We thank Josh Hegarty for their help with the field experiments and Youngjun Mo for the

602 development of Kronos x Gredho population. We also thank Xiaoqin Zhang for her help with the

603 introgression of the $A 10$ allele into Kronos and Saarah Kuzay for the phenotypic and genotypic

604 data for the Kronos x Gredho population. We thank Mohammed Guedira for help with

605 development and field evaluation of the LA95135 X SS-MPV57 population and Eduard

606 Akhunov, Alina Akhunova, Mary Guttieri and Brain Ward for early access to the genotypic data

607 for the winter wheat varieties.

608

609 Conflicts of interest/Competing interests

610 The authors declare no conflict of interests or competing interests

611

612 Author contribution statement 
613 PG conducted most of the experimental work and wrote the first version of the manuscript. JZ

614 contributed experimental work and many of the statistical analysis. KL contributed the $\mathrm{Y} 2 \mathrm{H}$

615 experiments. GBG and ND contributed the LA95135 x SS-MVP57 population and the

616 corresponding genotypic and phenotypic data. JC contributed the frequency of the D10A

617 polymorphism in Montana breeding lines. JD initiated and coordinated the project, contributed to

618 data analyses, and supervised PG. All authors reviewed the manuscript and provided

619 suggestions.

620

621 Availability of data and materials

622 All data and materials described in this paper are available from the corresponding author upon

623 request. The FT-A2 introgression in Kronos is being deposited in the National Small Grain

624 Collection (PI 699107). PI accession numbers are provided for all germplasm used when

625 available. The datasets retrieved and analyzed during the current study are available in the

626 T3/Wheat exome capture database (https://wheat.triticeaetoolbox.org/).

627

628 Code availability

629 Not applicable. 


\section{References}

Ali ML, Baenziger PS, Al Ajlouni Z, Campbell BT, Gill KS, Eskridge KM, Mujeeb-Kazi A, Dweikat I (2011) Mapping QTL for agronomic traits on wheat chromosome 3A and a comparison of recombinant inbred chromosome line populations. Crop Sci 51:553-566

Alvarez MA, Tranquilli G, Lewis S, Kippes N, Dubcovsky J (2016) Genetic and physical mapping of the earliness per se locus Eps- $A^{\mathrm{m}} 1$ in Triticum monococcum identifies EARLY FLOWERING 3 (ELF3) as a candidate gene. Funct Integr Genomic 16:365-382

Anzalone AV, Randolph PB, Davis JR, Sousa AA, Koblan LW, Levy JM, Chen PJ, Wilson C, Newby GA, Raguram A, Liu DR (2019) Search-and-replace genome editing without double-strand breaks or donor DNA. Nature 576:149-157

Brassac J, Muqaddasi QH, Plieske J, Ganal MW, Röder MS (2021) Linkage mapping identifies a non-synonymous mutation in FLOWERING LOCUS T (FT-B1) increasing spikelet number per spike. Sci Rep-Uk 11:1585

Campbell BT, Baenziger PS, Gill KS, Eskridge KM, Budak H, Erayman M, Dweikat I, Yen Y (2003) Identification of QTLs and environmental interactions associated with agronomic traits on chromosome 3A of wheat. Crop Sci 43:1493-1505

Cantu D, Yang B, Ruan R, Li K, Menzo V, Fu D, Chern M, Ronald PC, Dubcovsky J (2013) Comparative analysis of the defense response interactomes of rice and wheat. BMC Genomics 14:166

Darrier B, Rimbert H, Balfourier F, Pingault L, Josselin AA, Servin B, Navarro J, Choulet F, Paux E, Sourdille P (2017) High-resolution mapping of crossover events in the hexaploid wheat genome suggests a universal recombination mechanism. Genetics 206:1373-1388

DeWitt N, Guedira M, Lauer E, Murphy JP, Marshall D, Mergoum M, Johnson J, Holland JB, Brown-Guedira G (2021) Characterizing the oligogenic architecture of plant growth phenotypes informs genomic selection approaches in a common wheat population. . BMC Genomics 22:402

Dilbirligi M, Erayman M, Campbell BT, Randhawa HS, Baenziger PS, Dweikat I, Gill KS (2006) High-density mapping and comparative analysis of agronomically important traits on wheat chromosome 3A. Genomics 88:74-87 
Finnegan EJ, Ford B, Wallace X, Pettolino F, Griffin PT, Schmitz RJ, Zhang P, Barrero JM, Hayden MJ, Boden SA, Cavanagh CA, Swain SM, Trevaskis B (2018) Zebularine treatment is associated with deletion of FT-B1 leading to an increase in spikelet number in bread wheat. Plant Cell Environ 41:1346-1360

Fox J, Weisberg S (2019) An $\{\mathrm{R}\}$ companion to applied regression (3rd edition). Sage, Thousand Oaks, California, p https://socialsciences.mcmaster.ca/jfox/Books/Companion/

Gauley A, Boden SA (2021) Stepwise increases in FT1 expression regulate seasonal progression of flowering in wheat (Triticum aestivum). New Phytol 229:1163-1176

Guedira M, Brown-Guedira G, Van Sanford D, Sneller C, Souza E, Marshall D (2010)

Distribution of $R h t$ genes in modern and historic winter wheat cultivars from the Eastern and Central USA. Crop Sci 50:1811-1822

Halliwell J, Borrill P, Gordon A, Kowalczyk R, Pagano ML, Saccomanno B, Bentley AR, Uauy C, Cockram J (2016) Systematic investigation of FLOWERING LOCUS T-like Poaceae gene families identifies the short-day expressed flowering pathway gene, TaFT3 in wheat (Triticum aestivum L.). Front Plant Sci 7

He F, et al. (2019) Exome sequencing highlights the role of wild-relative introgression in shaping the adaptive landscape of the wheat genome. Nat Genet 51:896-904

Isham K, Wang R, Zhao W, Wheeler J, Klassen N, Akhunov E, Chen J (2021) QTL mapping for grain yield and three yield components in a population derived from two high-yielding spring wheat cultivars. Theor Appl Genet

Krasileva KV, et al. (2017) Uncovering hidden variation in polyploid wheat. Proc Natl Acad Sci U S A 114:E913-E921

Kuzay S, et al. (2019) Identification of a candidate gene for a QTL for spikelet number per spike on wheat chromosome arm 7AL by high-resolution genetic mapping. Theor Appl Genet 132:2689-2705

Li C, Lin H, Chen A, Lau M, Jernstedt J, Dubcovsky J (2019) Wheat VRN1, FUL2 and FUL3 play critical and redundant roles in spikelet development and spike determinacy. Development 146:dev175398 
Li C, Lin H, Dubcovsky J (2015) Factorial combinations of protein interactions generate a multiplicity of florigen activation complexes in wheat and barley. Plant J 84:70-82

Lin QP, Zong Y, Xue CX, Wang SX, Jin S, Zhu ZX, Wang YP, Anzalone AV, Raguram A, Doman JL, Liu DVR, Gao CX (2020) Prime genome editing in rice and wheat. Nat Biotechnol 38:582-585

Lv B, Nitcher R, Han X, Wang S, Ni F, Li K, Pearce S, Wu J, Dubcovsky J, Fu D (2014) Characterization of FLOWERING LOCUS T1 (FT1) gene in Brachypodium and wheat. PLoS One 9: e94171

Maccaferri M, et al. (2019) Durum wheat genome highlights past domestication signatures and future improvement targets. Nat Genet 51:885-895

Martinez AF, Lister C, Freeman S, Ma J, Berry S, Wingen L, Griffiths S (2021) Resolving a QTL complex for height, heading, and grain yield on chromosome $3 \mathrm{~A}$ in bread wheat. J Exp Bot 72:2965-2978

Pearce S, Vanzetti LS, Dubcovsky J (2013) Exogenous gibberellins induce wheat spike development under short days only in the presence of VERNALIZATION1. Plant Physiol 163:1433-1445

Poursarebani N, et al. (2015) The genetic basis of composite spike form in barley and 'MiracleWheat'. Genetics 201:155-165

Quintero A, Molero G, Reynolds MP, Calderini DF (2018) Trade-off between grain weight and grain number in wheat depends on GxE interaction: A case study of an elite CIMMYT panel (CIMCOG). Eur J Agron 92:17-29

Sakuma S, et al. (2019) Unleashing floret fertility in wheat through the mutation of a homeobox gene. Proc Natl Acad Sci USA 116:5182-5187

Shaw LM, Lyu B, Turner R, Li C, Chen F, Han X, Fu D, Dubcovsky J (2019) FLOWERING LOCUS T2 regulates spike development and fertility in temperate cereals. J Exp Bot 70:193-204 
713

714

715

716

717

718

719

720

721

722

723

724

725

726

727

728

729

730

731

732

733

734

Shaw LM, Turner AS, Herry L, Griffiths S, Laurie DA (2013) Mutant alleles of Photoperiod-1 in wheat (Triticum aestivum L.) that confer a late flowering phenotype in long days. PLoS One 8:e79459

Simmonds J, Scott P, Brinton J, Mestre TC, Bush M, Del Blanco A, Dubcovsky J, Uauy C (2016) A splice acceptor site mutation in TaGW2-A1 increases thousand grain weight in tetraploid and hexaploid wheat through wider and longer grains. Theor Appl Genet 129:1099-1112

Taoka K, et al. (2011) 14-3-3 proteins act as intracellular receptors for rice $H d 3 a$ florigen. Nature 476:332-325

Walkowiak S, et al. (2020) Multiple wheat genomes reveal global variation in modern breeding. Nature 588:277-283

Wang W, Pan QL, Tian B, He F, Chen YY, Bai GH, Akhunova A, Trick HN, Akhunov E (2019) Gene editing of the wheat homologs of TONNEAU1-recruiting motif encoding gene affects grain shape and weight in wheat. Plant J 100:251-264

Wilhelm EP, Turner AS, Laurie DA (2009) Photoperiod insensitive Ppd-Ala mutations in tetraploid wheat (Triticum durum Desf.). Theor Appl Genet 118:285-294

Zhang JL, Gizaw SA, Bossolini E, Hegarty J, Howell T, Carter AH, Akhunov E, Dubcovsky J (2018) Identification and validation of QTL for grain yield and plant water status under contrasting water treatments in fall-sown spring wheats. Theor Appl Genet 131:17411759 


\section{Tables}

736

737 Table 1. Frequency of the FT-A2 alleles in different germplasm collections

\begin{tabular}{|c|c|c|c|c|c|c|}
\hline Species & Ploidy & No. acc. & A $10 \%$ & $\mathrm{D} 10 \%$ & A10 & D10 \\
\hline T. urartu & $2 \mathrm{x}$ & 89 & $0.0 \%$ & $100.0 \%$ & 0 & 89 \\
\hline T. turgidum ssp. dicoccoides & $4 \mathrm{x}$ & 82 & $0.0 \%$ & $100.0 \%$ & 0 & 82 \\
\hline T. turgidum ssp. dicoccon & $4 \mathrm{x}$ & 32 & $0.0 \%$ & $100.0 \%$ & 0 & 32 \\
\hline T. turgidum ssp. durum & $4 \mathrm{x}$ & 417 & $0.7 \%$ & $99.3 \%$ & 3 & 414 \\
\hline T. aestivum Exome capture a & $6 x$ & 238 & $59.7 \%$ & $40.3 \%$ & 142 & 96 \\
\hline T. aestivum US winter wheats ${ }^{b}$ & $6 x$ & 126 & $81.7 \%$ & $18.3 \%$ & 103 & 23 \\
\hline T. aestivum Spring DUF ${ }^{\mathrm{c}}$ & $6 x$ & 149 & $58.4 \%$ & $41.6 \%$ & 87 & 62 \\
\hline T. aestivum Spring DUS ${ }^{\mathrm{d}}$ & $6 x$ & 192 & $34.4 \%$ & $65.6 \%$ & 66 & 126 \\
\hline
\end{tabular}

$738 \quad{ }^{\mathrm{a}} \mathrm{He}$ et al. 2019

$739 \mathrm{~b}$ T3/Wheat

$740 \quad{ }^{\mathrm{c}}$ Zhang et al. 2018

$741 \mathrm{~d}$ Zhang et al. $2018+99$ breeding lines from MT

742

743

744

745 
746 Table 2. Effects of $F T-A 2, P P D-A 1$ and $R H T-B 1$ on plant height (HT), days to heading (DTH)

747 and spikelet number per spike (SNS). Three-way ANOVA with $P$ values of the main effects and

748 least-square means (LSmeans). Error bars are s.e.m. ns $=$ not significant, $*=P<0.05, * *=P<$

$7490.01, * * *=P<0.001$. All the interactions were non-significant.

\begin{tabular}{|c|c|c|c|c|}
\hline & & $\begin{array}{l}\text { Plant height } \\
(\mathrm{HT}, \mathrm{cm})\end{array}$ & $\begin{array}{l}\text { Days to heading } \\
\text { (DTH) }\end{array}$ & $\begin{array}{c}\text { Spikelet No./spike } \\
\text { (SNS) }\end{array}$ \\
\hline$F T-A 2$ & Kronos (D10) & $113.4 \pm 3.2$ & $130.5 \pm 0.9$ & $25.1 \pm 0.5$ \\
\hline LSmean \pm s.e.m. & Gredho (A10) & $118.3 \pm 2.2$ & $130.6 \pm 0.6$ & $26.7 \pm 0.3$ \\
\hline Three-way ANOVA & Pvalue & ns & ns & $*$ \\
\hline$P P D-A 1$ & Kronos & $108.1 \pm 2.3$ & $120.8 \pm 0.6$ & $22.6 \pm 0.4$ \\
\hline LSmean \pm s.e.m. & Gredho & $121.6 \pm 2.6$ & $141.0 \pm 0.7$ & $29.6 \pm 0.4$ \\
\hline Three-way ANOVA & Pvalue & $* * *$ & $* * *$ & $* * *$ \\
\hline$R h t-B 1$ & Kronos & $97.1 \pm 2.5$ & $131.5 \pm 0.7$ & $26.2 \pm 0.5$ \\
\hline LSmean \pm s.e.m. & Gredho & $131.4 \pm 2.8$ & $130.2 \pm 0.8$ & $25.8 \pm 0.4$ \\
\hline Three-way ANOVA & Pvalue & $* * *$ & $*$ & ns \\
\hline
\end{tabular}

750

751

752 
753 Table 3. Comparisons of Near isogenic lines with the FT-A2 A10 and D10 alleles in field 754 experiments at UC Davis in 2020 and 2021.

\begin{tabular}{|c|c|c|c|c|c|c|c|}
\hline Davis 2020 & Allele & $\mathrm{N}$ & SNS & GN & $\begin{array}{l}\text { Grains/ } \\
\text { spikelet }\end{array}$ & $\begin{array}{l}\mathrm{GW} \\
\mathrm{mg}\end{array}$ & $\begin{array}{l}\text { Yield / } \\
\text { spike g }\end{array}$ \\
\hline \multicolumn{8}{|l|}{ Davis 2020} \\
\hline $\mathrm{H} 2-14$ & D10 & $10^{\text {a }}$ (54 spikes) & 20.27 & 59.22 & 2.92 & 55.81 & 3.31 \\
\hline \multirow[t]{3}{*}{$\mathrm{H} 2-14$} & A10 & $10^{\text {a }}$ (38 spikes) & 21.92 & 70.77 & 3.23 & 56.78 & 4.07 \\
\hline & A10 & $\%$ increase & $7.9 \%$ & $19.6 \%$ & $10.6 \%$ & $1.8 \%$ & $22.9 \%$ \\
\hline & & $t$-TEST & 0.0016 & 0.0004 & 0.0016 & 0.55 & 0.0018 \\
\hline $\mathrm{H} 2-23$ & D10 & $10^{\text {a }}$ (39 spikes) & 19.36 & 56.31 & 2.89 & 54.47 & 3.07 \\
\hline \multirow[t]{3}{*}{$\mathrm{H} 2-23$} & A10 & $10^{\text {a }}$ (38 spikes) & 23.11 & 81.06 & 3.51 & 54.21 & 4.41 \\
\hline & A 10 & $\%$ increase & $19.1 \%$ & $44.0 \%$ & $21.5 \%$ & $-0.6 \%$ & $43.2 \%$ \\
\hline & & ANOVA $P$ & $<0.0001$ & $<0.0001$ & 0.0003 & 0.88 & 0.0002 \\
\hline \multicolumn{8}{|c|}{ Tulelake 2020} \\
\hline $\mathrm{H} 2-14$ & D10 & 27 spikes & 17.15 & 44.11 & 2.57 & 38.26 & 1.69 \\
\hline \multirow[t]{3}{*}{ H2-14 } & A10 & 23 spikes & 17.83 & 46.48 & 2.61 & 40.49 & 1.88 \\
\hline & & $\%$ increase & $4.0 \%$ & $5.4 \%$ & $1.4 \%$ & $5.8 \%$ & $10.5 \%$ \\
\hline & & ANOVA $P$ & 0.0004 & 0.2788 & 0.7665 & 0.2487 & 0.1348 \\
\hline \multicolumn{8}{|l|}{ Davis 2021} \\
\hline $\mathrm{BC}_{4} \mathrm{~F}_{2: 4}$ & D10 & $12^{\mathrm{b}}$ (96 spikes) & 18.52 & 67.85 & 3.67 & 60.34 & 4.09 \\
\hline \multirow[t]{3}{*}{$\mathrm{BC}_{4} \mathrm{~F}_{2: 4}$} & A10 & $12^{\mathrm{b}}$ (96 spikes) & 19.58 & 72.15 & 3.69 & 55.61 & 4.01 \\
\hline & & $\%$ difference & $5.7 \%$ & $6.3 \%$ & $0.5 \%$ & $-7.8 \%$ & $-2.0 \%$ \\
\hline & & ANOVA $P$ & 0.0011 & 0.0168 & 0.7919 & 0.0002 & 0.2883 \\
\hline
\end{tabular}

$755{ }^{a}$ Experimental units were $1 \mathrm{~m}$ rows, with 3-5 spikes measured per row.

$756 \mathrm{~b}$ Experimental units were 4 row plots $\left(1.86 \mathrm{~m}^{2}\right)$, with 8 spikes measured per plot. 
758 Table 4 Critical recombinant $\mathrm{BC}_{1} \mathrm{~F}_{5}$ from Davis 2019-2020 field seasons. All lines except

759 recombinant H2 \#6 were evaluated in the 2019 field season. Comparisons of SNS for statistical

760 significance are only between sister lines segregating for the heterozygous region.

\begin{tabular}{|c|c|c|c|c|c|c|c|c|c|c|c|}
\hline \multirow{2}{*}{ Marker } & \multirow{2}{*}{ Chr. 3AS CS } & \multirow{2}{*}{$\begin{array}{l}\mathrm{H} 2 \\
\# 6\end{array}$} & \multirow{2}{*}{$\begin{array}{l}\text { H2-6 } \\
\# 14-5\end{array}$} & \multicolumn{3}{|c|}{$\mathrm{H} 2-14$} & \multicolumn{3}{|c|}{$\mathrm{H} 2-23$} & \multicolumn{2}{|c|}{ D12 11-1 } \\
\hline & & & & $\# 17-2$ & $\# 1-3$ & $\# 18-5$ & $\# 47-1$ & $\# 47-5$ & $\# 53-4$ & \#71-1 & \#73-1 \\
\hline $3 \mathrm{~A}-117.83$ & $117,828,272$ & $\mathrm{H}$ & $\mathrm{H}$ & $\mathrm{H}$ & $\mathrm{H}$ & $\mathrm{H}$ & K & $\mathrm{H}$ & $\mathrm{H}$ & $\mathrm{H}$ & K \\
\hline $3 \mathrm{~A}-120.23$ & $120,227,651$ & $\mathrm{H}$ & G & $\mathrm{H}$ & $\mathrm{K}$ & $\mathrm{H}$ & K & $\mathrm{K}$ & $\mathrm{G}$ & K & K \\
\hline $3 \mathrm{~A}-121.48$ & $121,482,459$ & $\mathrm{H}$ & G & $\mathrm{H}$ & $\mathrm{K}$ & $\mathrm{G}$ & $\mathrm{K}$ & $\mathrm{K}$ & G & K & K \\
\hline $3 \mathrm{~A}-121.65$ & $121,646,195$ & $\mathrm{H}$ & G & $\mathrm{H}$ & $\mathrm{K}$ & $\mathrm{G}$ & $\mathrm{K}$ & $\mathrm{K}$ & G & K & K \\
\hline $3 \mathrm{~A}-122.54$ & $122,540,617$ & $\mathrm{H}$ & G & $\mathrm{H}$ & K & G & K & $\mathrm{K}$ & G & K & K \\
\hline FT-A2-L4 & $122,542,102$ & $\mathrm{H}$ & G & $\mathrm{H}$ & $\mathrm{K}$ & $\mathrm{G}$ & K & $\mathrm{K}$ & G & K & K \\
\hline SNS PHENO. & $124,172,909$ & $\mathrm{H}$ & G & $\mathrm{H}$ & $\mathrm{K}$ & G & K & $\mathrm{K}$ & $\mathrm{G}$ & K & K \\
\hline FT-A2-R1 & $125,094,949$ & $\mathrm{H}$ & G & $\mathrm{H}$ & K & G & K & $\mathrm{K}$ & G & K & K \\
\hline $3 \mathrm{~A}-125.40$ & $125,402,254$ & $\mathrm{H}$ & G & $\mathrm{H}$ & $\mathrm{K}$ & $\mathrm{G}$ & $\mathrm{K}$ & $\mathrm{K}$ & G & $\mathrm{K}$ & $\mathrm{K}$ \\
\hline $3 \mathrm{~A}-126.57$ & $126,567,437$ & $\mathrm{~K}$ & $\mathrm{~K}$ & $\mathrm{H}$ & $\mathrm{K}$ & $\mathrm{G}$ & $\mathrm{K}$ & $\mathrm{K}$ & $\mathrm{G}$ & $\mathrm{K}$ & $\mathrm{K}$ \\
\hline $3 \mathrm{~A}-127.82$ & $127,821,835$ & $\mathrm{~K}$ & $\mathrm{~K}$ & $\mathrm{~K}$ & $\mathrm{~K}$ & G & $\mathrm{H}$ & $\mathrm{K}$ & $\mathrm{G}$ & $\mathrm{K}$ & $\mathrm{H}$ \\
\hline \multicolumn{2}{|c|}{ Number of plants in PT } & 34 & 83 & 71 & 72 & 79 & 70 & 74 & 75 & 80 & 81 \\
\hline \multicolumn{2}{|c|}{ SNS Avg. Gredho allele (G) } & 22.1 & 23.9 & 23.5 & 22.4 & 24.2 & 22.4 & 22.7 & 24.1 & 22.3 & 23.1 \\
\hline \multicolumn{2}{|c|}{ SNS Avg. Kronos allele (K) } & 21.6 & 23.2 & 21.7 & 22.5 & 23.0 & 21.9 & 22.4 & 24.3 & 21.7 & 22.4 \\
\hline \multicolumn{2}{|l|}{$P$ values $K$ vs $G$} & $3 e-05$ & NS & 0.004 & NS & NS & NS & NS & NS & NS & NS \\
\hline
\end{tabular}

761

762 
763 Table 5 Spikelet number per spike (SNS) evaluation of $\mathrm{BC}_{1} \mathrm{~F}_{6}$ homozygous sister lines from 764 recombinant line H2-18 \#28-4 in Tulelake 2020. Sister line \#28-4-\#1 carried a proximal Kronos 765 chromosome segment and sister line \#28-4-\#3 a proximal Gredho chromosome segment. Lines 766 \#17-2-18 (FT-A2 D10) and \#17-2-22 (FT-A2 A10) were included as controls.

\begin{tabular}{|c|c|c|c|c|c|}
\hline Marker & Chr.3AS CS & $\begin{array}{r}\mathrm{H} 2-18 \\
\# 28-4-1 \\
\end{array}$ & $\begin{array}{c}\mathrm{H} 2-18 \\
\# 28-4-3 \\
\end{array}$ & $\begin{array}{c}\text { H2-14 } \\
\# 17-2-18\end{array}$ & $\begin{array}{r}\mathrm{H} 27167 \\
\# 17-2-22 \\
\end{array}$ \\
\hline $3 \mathrm{~A}-117.82$ & $117,828,272$ & $\mathrm{G}$ & G & $\mathrm{K}$ & G \\
\hline $3 \mathrm{~A}-120.2$ & $120,227,651$ & G & G & K & G \\
\hline $3 \mathrm{~A}-121.4$ & $121,482,459$ & G & G & $\mathrm{K}$ & G \\
\hline $3 \mathrm{~A}-121.64$ & $121,646,195$ & G & G & $\mathrm{K}$ & G \\
\hline $3 \mathrm{~A}-122.540$ & $122,540,617$ & G & G & K & G \\
\hline FT-A2-L4 & $122,542,102$ & G & G & $\mathrm{K}$ & G \\
\hline FT-A2 & $124,172,909$ & G & G & $\mathrm{K}$ & G \\
\hline SNS PHENO & & G & G & $\mathrm{K}$ & G \\
\hline FT-A2-R1 & $125,094,949$ & G & G & K & G \\
\hline $3 \mathrm{~A}-125.4$ & $125,402,254$ & $\mathrm{~K}$ & G & $\mathrm{K}$ & G \\
\hline $3 \mathrm{~A}-126.5$ & $126,567,437$ & $\mathrm{~K}$ & G & $\mathrm{K}$ & G \\
\hline $3 \mathrm{~A}-127.8$ & $127,821,835$ & $\mathrm{~K}$ & G & $\mathrm{K}$ & $\mathrm{K}$ \\
\hline Number of pla & & 40 & 42 & 43 & 40 \\
\hline SNS Avg & & 17.68 & 17.87 & 16.94 & 17.94 \\
\hline \multicolumn{2}{|c|}{$P$ values D10 $(\mathrm{K})$ vs A10 (G) } & \multicolumn{2}{|c|}{0.287} & \multicolumn{2}{|c|}{$1.78 \mathrm{E}-09$} \\
\hline
\end{tabular}

768

769

770 


\section{$771 \quad$ Figure legends}

772

773 Fig. 1 Comparison between FT-A2 A10 (SS-MVP57) and D10 (LA95135) alleles n winter

774 wheat. a Days to heading. b Spikelet number per spike. c Grain number per spike. d Grain

775 number per spikelet (fertility). e Average spike yield. Bars are least square means from a

776 factorial ANOVA including $P P D-\mathrm{D} 1, R H T-D 1$ and $W A P O-A 1$ as factors. Error bars are s.e.m.

$777 \mathrm{~ns}=$ not significant, $* P=0.05, * * P=0.01, * * * P=0.001$. 


\section{Figures}
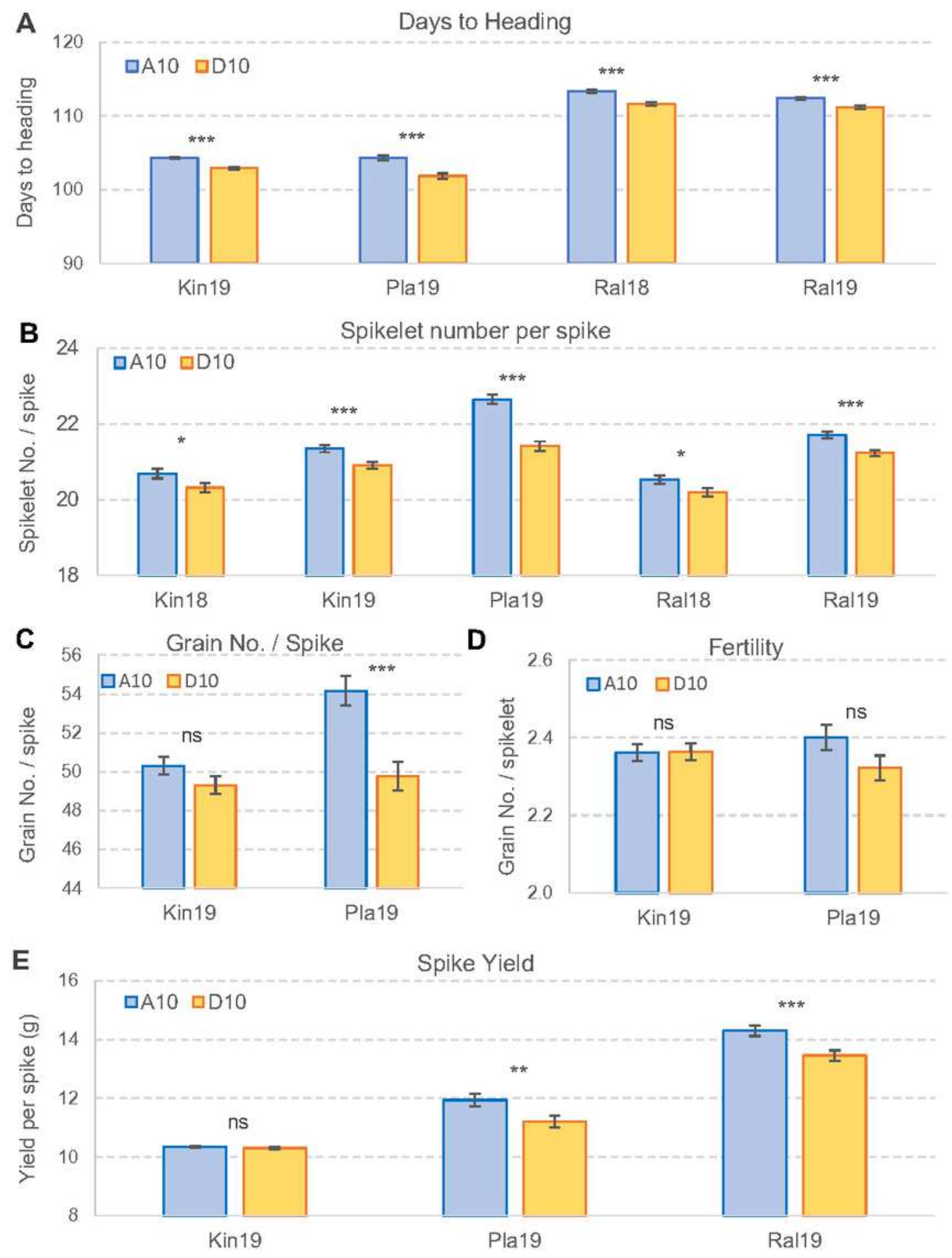

Figure 1

Comparison between FT-A2 A10 (SS-MVP57) and D10 (LA95135) alleles n winter wheat. a Days to heading. b Spikelet number per spike. c Grain number per spike. d Grain number per spikelet (fertility). e 
Average spike yield. Bars are least square means from a factorial ANOVA including PPD-D1, RHT-D1 and WAPO-A1 as factors. Error bars are s.e.m. ns $=$ not significant, ${ }^{*} P=0.05, * \star P=0.01, \star \star \star ~ P=0.001$.

\section{Supplementary Files}

This is a list of supplementary files associated with this preprint. Click to download.

- SupplementaryAppendix1GlennDubcovsky.xlsx

- SupplementaryTablesandFiguresGlennDubcovsky.pdf 